\title{
AC 2011-1639: CHALLENGES AND BENEFITS OF ESTABLISHING AN ENGINEERS WITHOUT BORDERS CHAPTER AT WWU
}

\section{Forrest Alden Copeland, Western Washington University}

While completing his undergraduate degree in Manufacturing Engineering Technology, Forrest Copeland helped establish the Engineers Without Borders student chapter at Western Washington University in 2006. Copeland completed his degree in 2009 and graduated as the Engineering department's outstanding senior. He also received the Presidential Scholar Award due, in part, to his work with the Engineers Without Borders student club. Shortly after graduation, Copeland traveled with four other students and one professional to conduct an assessment trip in Guatemala for the project. Copeland is currently an industrial engineer at a Bellingham Washington hardwood plywood manufacturing facility.

\section{Derek M. Yip-Hoi, Western Washington University}

Derek Yip-Hoi has a Ph.D. in Mechanical Engineering from the University of Michigan. He has broad experience in $\mathrm{CAD} / \mathrm{CAM}$ and geometric and solid modeling from research and teaching experiences at $\mathrm{UM}$ and the University of British Columbia. Currently he coordinates the CAD/CAM instruction in the Engineering Technology Department at Western Washington University. 


\title{
Challenges and Benefits of Establishing an Engineers Without Borders Student Chapter at Western Washington University
}

\begin{abstract}
In 2005 students at Western Washington University established a chapter of Engineers without Borders (EWB). The chapter is hosted by the university’s Engineering Technology (ET)

Department with many of the initial members and faculty coming from this department. This has proved challenging to WWU's chapter because the ET department does not include a program in Civil Engineering Technology. Consequently this has required the student chapter to reach out to recruit students from other departments within the University as well as to professional nonstudent mentors in the greater Bellingham community for expertise in planning and implementing projects. This paper describes the challenges, advantages, and opportunities of working with a multidisciplinary student group, and professional mentors, in developing a water quality solution for a rural community in Guatemala.
\end{abstract}

\section{Introduction}

Engineers without Borders (EWB-USA) is a non-profit organization that was established at the University of Colorado Civil in 2002. As described in the mission statement "EWB-USA supports community-driven development programs worldwide by collaborating with local partners to design and implement sustainable engineering projects, while creating transformative experiences and responsible leaders." ${ }^{1}$ The organization is currently involved in 350 projects in 45 countries with an emphasis on providing clean water to communities.

In 2006, students at Western Washington University (WWU), located in Bellingham Washington, established a chapter of EWB. The chapter was initially formed with the guidance of several professional mentors who were involved in chapters at other universities while they were students. This began a beneficial collaboration between this professional community in Bellingham and the WWU chapter of EWB. Civil Engineering departments typically provide much of the membership and faculty support for EWB student chapters. Since WWU does not have a CE or CET department, WWU's student chapter has relied heavily on support and mentorship from this group. This has helped to provide valuable expertise in areas of specialization typical to EWB projects including surveying, wetland design, and structural engineering that were beyond the student's exposure at WWU. Many of these experts also participate in a Professional EWB chapter in Bellingham. This presents a unique opportunity for collaboration between a student and professional chapter which can be explored as a model for forwarding the EWB agenda. This paper will in part describe the experiences and processes used by the chapter in using this network to achieve the goals of its project work.

This paper will also highlight one of the strengths of the WWU chapter which is the high interest and participation from a diverse section of the student body. While there are Engineering Technology students actively participating in the project, there are other highly active student members pursuing degrees in environmental science, Spanish, community health, industrial design, business, and education. This diversity has engendered a holistic approach to the 
chapter's activities that is in keeping with EWB's vision for project work. This paper will highlight the structure and operation of WWU's EWB chapter and how the project team is able to incorporate ideas from students with a variety of backgrounds into forwarding the goals of the chapter. It further explains how the mentor and student groups work together in developing a water quality solution for the community Candelaria Camposanto in rural Guatemala. The paper will end by highlighting the key challenges that have been faced and some opportunities that the WWU environment provides for growing a vibrant EWB experience.

\section{Creating a Broad Student Membership}

EWB projects are largely focused on water quality problems faced by economically challenged communities in developing countries. These and other projects that require the construction of structures have a strong Civil Engineering requirement. This created a major challenge in establishing a EWB chapter at WWU's ET department. Here the programs offered are in the disciplines of manufacturing, electronics and automotive design. While basic engineering courses in Statics and Strength of Materials provide foundational training, the more advanced courses in areas such as structural engineering, hydrology, fluid mechanics, surveying and soil engineering are missing. To counteract this deficiency the founders of the chapter targeted the creation of a chapter that drew from the diversity of disciplines available at WWU, a liberal arts college by tradition. This approach provided a solid foundation for many of the non-technical aspects required by EWB projects that warrant the use of language, cultural, environmental, educational, sustainability and health expertise.

EWB-WWU originally struggled to find a project that was captivating enough to hold student's attention. The chapter began several local projects including a water supply system for a Boy Scout camp, a waste water treatment solution for a Native American school and an anaerobic bio digester to convert campus food waste into methane. These projects were not effective in holding student interest and also diverged from EWB-USA's primary focus on international projects. In the spring of 2008, EWB-WWU officially adopted a new international project proposed by a local civil engineer and a post-baccalaureate student. Both of these members had previous experience working in Guatemala. The project situated in rural Guatemala entailed developing a solution to eliminate river contamination from clothes washing and personal hygiene activities. The student, a Peace Corp volunteer while in Guatemala had in fact constructed a washing station to solve a similar problem in a nearby community ${ }^{2}$.

However, even with this new international project, student membership within the ET department was still difficult to sustain at levels large enough to meet the planning, reporting and fundraising requirements for an EWB project. This was when the decision was made to expand recruiting beyond ET to target a broad range of departments within the university. Prospective students were encouraged to attend an informative meeting at the beginning of the academic school year to learn about the project in Guatemala and how they could get involved. The focus of this meeting was to present the problem of water quality contamination faced by the host community in a broad enough sense so that students from many different disciplines would feel that they could contribute in a meaningful way. As part of this strategy the brand name "Engineers without Borders" was de-emphasized in favor of the name "Guatemala Sustainability Project". It was felt that this would help prevent dissuading non-engineering students from 
joining the club due to the simple misunderstanding that the club is based solely on engineering. This recruitment method is usually most effective in the fall, when students are returning from summer vacations. However it is undertaken at the beginning of each academic quarter to ensure continual recruitment.

It should be pointed out that in addition to the unique challenges the EWB chapter faced at WWU, it also faced challenges typical of this type of student group. Retention is often very difficult for student organizations as most students carry full course loads for the duration of their undergraduate studies in addition to several extracurricular activities and sometimes jobs. The latter is particularly true for many ET students who are continually struggling to balance family life and their studies. Complicating things is the presence of almost 200 official Associated Student clubs on campus that compete for student's time and attention.

\section{Club Structure - Small Teams}

Due to the success of the recruitment effort outlined above, the first informational meeting in the fall of 2008 was well attended by students from many different disciplines. Student membership rose to nearly twenty five with a core group of around five students who took on leadership roles. It quickly became apparent that the chapter's project activities would need to be broken down to allow students to contribute within smaller groups to effectively complete tasks. This was also vital to effectively tap the talents of a group of students from a wide variety of backgrounds, all possessing different interests and academic specializations. Additionally large tasks could be divided and assigned as finite tasks to individuals or pairs within each of the small groups.

The chapter's membership was divided into four groups. Each was designed to collect together like minded students in small functional teams which focused on, community health, technical, cultural, and administrative. EWB National strongly encourages this type of multidisciplinary approach to international projects, rather than focusing exclusively on engineering and technical aspects. A veteran EWB-WWU member served as a team lead for each of the four teams. This individual was responsible for leading a small group meeting each week and reporting back to the general club with updates and questions or discussions to address with the other three teams. This method worked well because it allowed students to work on what they were comfortable with while learning about the other teams at the same time.

Although students are encouraged to work on teams in which they have some background and prerequisite knowledge, it is not a mandatory requirement. As an example, EWB-WWU originally did not have any students whose studies directly applied to the area of community health. The leaders for this team ended up being a pair of Industrial Design students who wanted to learn more about community health and nursing. After more recruitment, the health team was supplemented with community health majors. Both WWU faculty and a local nurse acted as professional advisors for the team. Through this process the Industrial Design students were able to learn a great deal about community health, a field which is not covered in their academic curriculum.

EWB-WWU usually meets once a week and often devotes a significant amount of this time to small team meetings. The general meeting is called to order by the president who covers items 
of general interest. This is followed by either small team meeting time or a lecture or discussion lead by one of these teams. Teams are given alternating weeks to cover information that would be helpful for the entire membership to understand. This included topics such as basic Spanish skills, water treatment fundamentals, rural health practices, fundraising methods, or indigenous construction techniques. The chapter has also hosted fun events focusing on relevant issues on the project in order to welcome new students to the organization as well as to reward current members for their hard work. There have been documentary movie nights as well as potlucks featuring Guatemalan cuisine.

Small team collaboration can be epitomized in an example of collaboration between the cultural team and the health and technical teams. Both the health and technical teams developed sets of questions for the host community prior to the chapter's assessment trip to Guatemala in the summer of 2009. These questions were submitted to the cultural team who began translating and preparing for a conference call to the community. Representatives from each team gathered for a conference call to Guatemala which was carried out in Spanish by members of the cultural team. Health and technical team members were present during the call to offer assistance or answer questions from the community while the cultural team acted as translators for the entire conversation. These conference calls were extremely helpful during the assessment trip planning phase as well as the preliminary design phase of the project and continue to be a great help for in planning for the project.

\section{Professional Mentorship - Technical}

Despite the academic variety of the student members, there are areas of specialization including surveying, wetland design, and civil engineering that are beyond the student's area of knowledge. Therefore, the student chapter relies heavily on mentorship from experts in the community. Prior to the June 2009 assessment trip two local civil engineers helped prepare the students by explaining and demonstrating basic surveying techniques during both a lecture and a hands-on workshop. This information was vital to the successful mapping of the host communities land and proposed site for a washing structure (Lavanderia) during the 2009 assessment trip to Guatemala. During the trip the entire village was mapped using both GPS and conventional trigonometry based surveying. The field data was compiled in AutoCAD to document the survey as shown below in Figure 1.

The student chapter also utilized advice and guidance from professionals during the preliminary design phase of the project. Students worked together to develop water usage estimates, treatment methods, plumbing specifications and structural design. When students had questions regarding specific design features the professional mentors were consulted. The EWB-WWU technical team in the end selected and completed a preliminary design for a Lavanderia for the host community in Guatemala. Gray water effluent from washing activities will be treated using subsurface flow wetlands. These wetlands were designed with the help of two Engineers in Training from the community. These two mentors explained the principals of this type of water treatment and worked through the sizing and design specifications with the students on the technical team. Again, given the limited exposure that WWU-ET students receive to civil engineering curriculum, this type of design work would be difficult to complete without the close working relationship that exists with the chapter's mentors. 


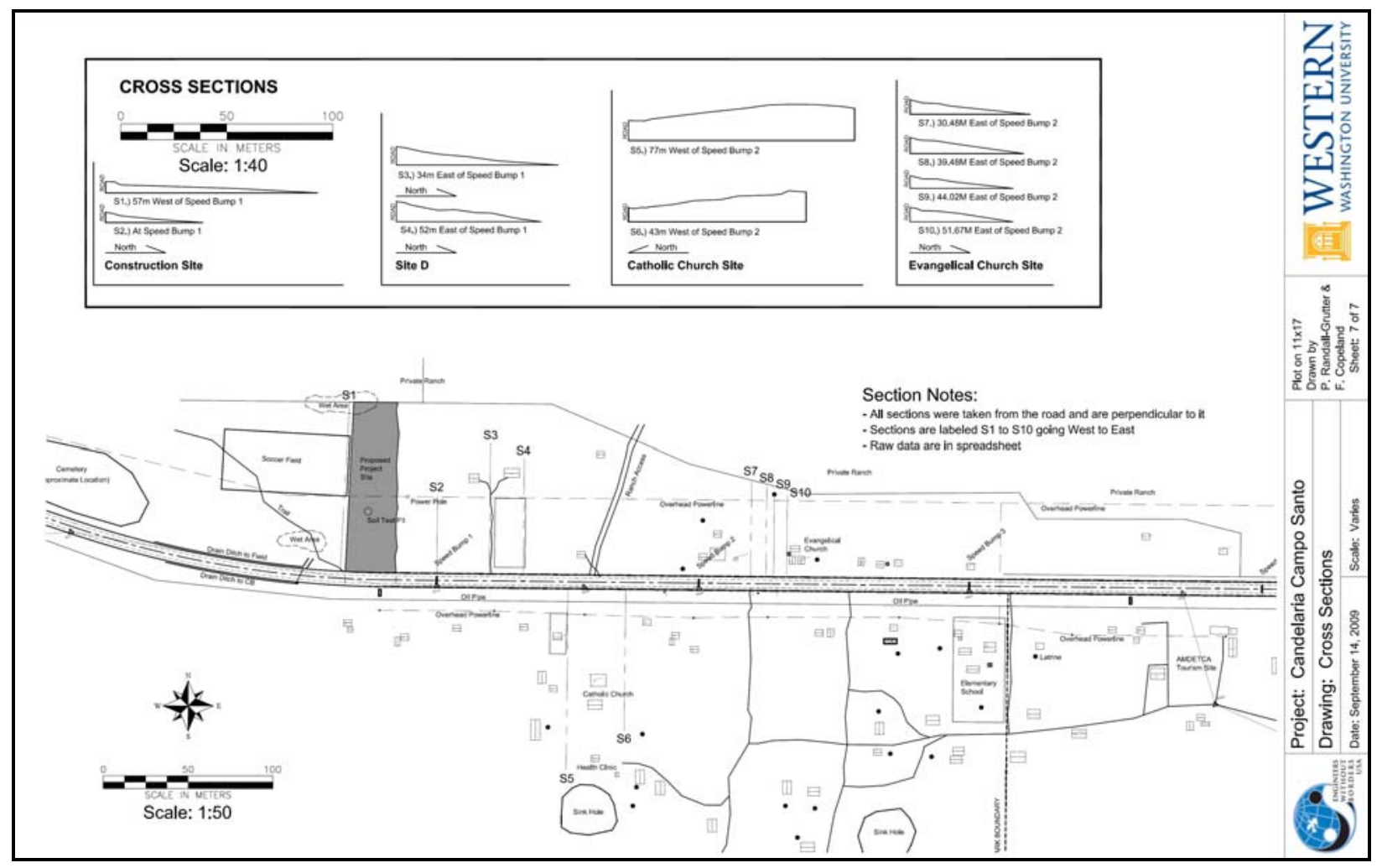

Figure 1: Auto-CAD Map Generated After June 2009 Assessment Trip

Students in the engineering technology department of the university do have a strong CAD background. Some are required to take several courses focused on 3D CAD modeling and drafting using a variety of software packages. Using these skills, the technical team is capable of drafting and rendering various aspects of the proposed clothes washing facility using a CAD program such as CATIA. One example of a drawing from the preliminary design can be seen in Figure 2.

\section{Professional Mentorship - Administrative}

In addition to technical help offered by the professional mentors during the assessment trip and the design phase of the project, professionals have also contributed to the administrative success of the student chapter. The assistance offered by Gary Fortenberry, president of the local professional chapter of EWB and a project manager at CH2M Hill, has been paramount to the success of the student chapter. He has met with the student chapter leadership to share his experience with project management with the student chapter. These skills, including task divisions, timeline goals, and documentation, have been extremely valuable for completing the design deadlines set by EWB National. Additionally Fortenberry and the student chapter president at the time Forrest Copeland collaborated on several fundraising presentations at local Rotary clubs. These efforts succeeded in securing a \$1000 donation in addition to building a greater understanding of EWB in the greater Bellingham community. Fortenberry attends at least one key recruitment meeting every year to offer advice and encouragement to prospective student chapter members. 
EWB-WWU also relies on the support and advice of the student chapter advisor, Professor Derek Yip-Hoi. Professor Yip-Hoi became involved with the student chapter in the fall of 2008. His assistance has added a great deal of stability and continuity to the club. One of the greatest challenges facing any student organization is retention between academic years as students constantly cycle in and out of the University. Having a dedicated advisor has helped ensure EWB-WWU stays on track with its long term goals between academic years as new students join the club. Professor Yip-Hoi also helps guide the officers of the chapter by offering leadership and overall club strategy advice during regular meetings with the chapter president.

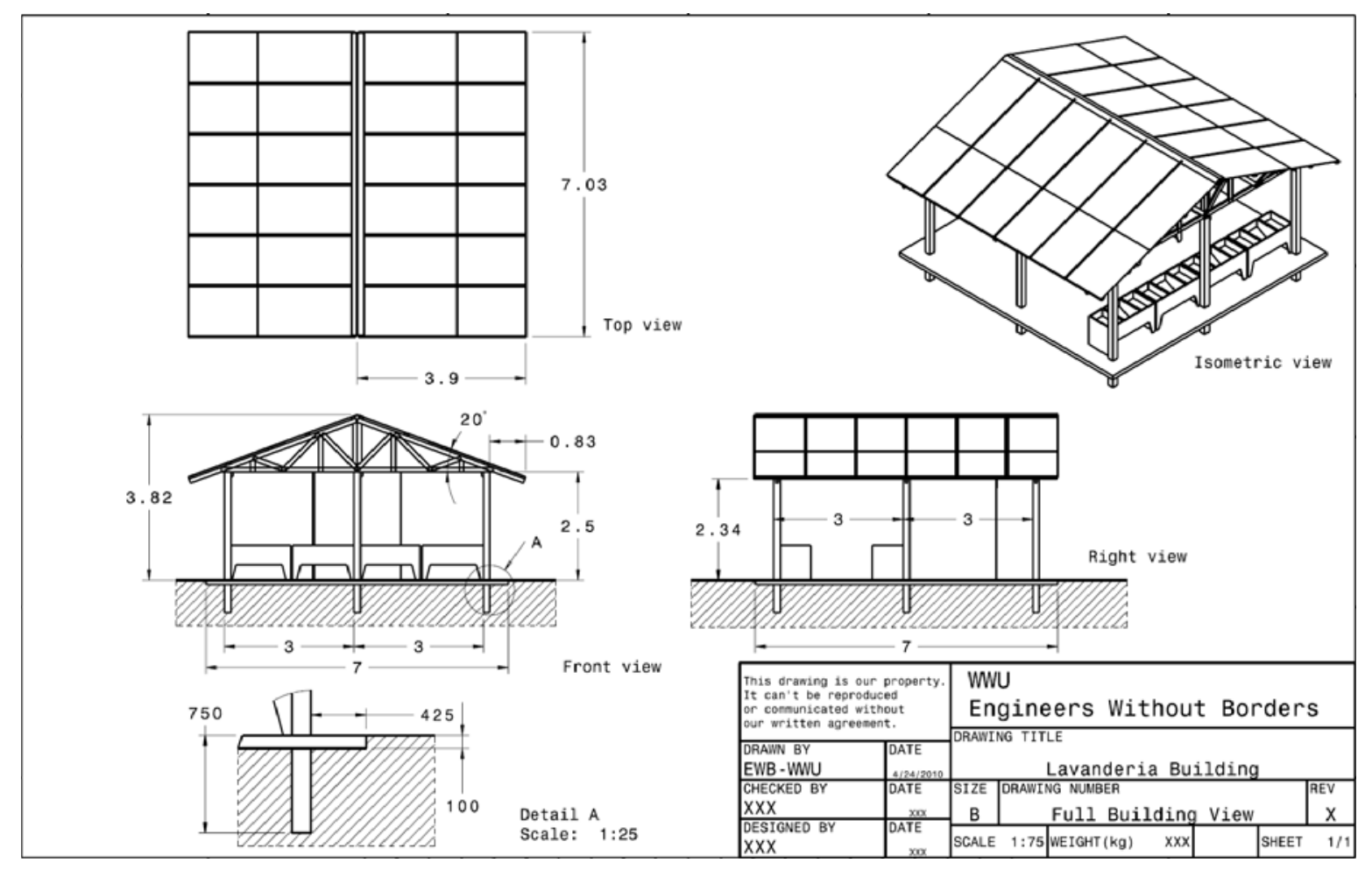

Figure 2: CATIA Drawing for the Proposed Clothes Washing Station

\section{Challenges}

Despite the benefits of working in small teams and relying on professional mentors described above, EWB-WWU has encountered some challenges in its work as summarized below.

- Dependence on Professional Mentors. While working with professional mentors has been necessary to supplement student's knowledge and abilities, it is a concern that the chapter may become too reliant on professional input. Students need to understand the technical principals taught by the professionals to ensure design work is done competently, but must not rely on the professionals to complete the work. Students need to understand why specific engineering decisions are made in order to justify the decisions in the design documents submitted to EWB National and to be capable of answering independently follow up questions posed by technical project reviewers. 
- Silo Effect of Small Teams. The small teams can result in too much stratification of the club. It is important that all student members contribute to the success of the project and the overall progress achieved by the club. Therefore the chapter meeting times are very important to prevent divergence between each team. Additionally all chapter members need to work together on fundraising and out reach activities which further helps to integrate the small groups together into a cohesive student chapter.

- Balancing Small Team Workloads. EWB-WWU continually struggles to balance the workloads of each of the small teams. During the design phase of the project many students in the community health and cultural teams found it difficult to stay involved as most of the activities of chapter's meetings were focused on technical design work. The cultural team students were consulted for their input regarding social design factors and were extremely helpful in communicating technical questions between the design team and the community in Guatemala. However, workload balancing remains a challenge for EWB-WWU.

- Chapter Continuity. Before student members graduate or leave the chapter, it is important that they pass on documentation and ideas to the rest of the chapter. This has mostly been accomplished through the extensive design documents that EWB National requires. By completing these comprehensive documents, students are able to leave their work in the hands of the club. Additionally data continuity is achieved through the use of an online file sharing website hosted by the University. Regarding leadership continuity, chapter elections are held in the spring to ensure the returning students have a clearly defined leadership in place for the fall quarter.

\section{Opportunities}

The EWB-WWU experience has already taken advantage of a diverse university environment and committed professional mentors in helping to sustain its activities. However, more can be done on both fronts. Opportunities exist within WWU to increase the involvement of a broader spectrum of faculty in the chapter's work. Linking project activities with academics would be one way to achieve this. An example would be to use the Guatemala project as a case study or term project for a project management course offered by the university's Business School. Another natural link exists with courses offered in the university's School of the Environment that deal with water quality.

Collaboration with other student chapters is also an area that can benefit EWB-WWU. One opportunity has already been pursued with the ET department's Society of Manufacturing Engineers. Students from this chapter designed and fabricated a bicycle driven mechanical washer, a project proposed by EWB-WWU for possible implementation as a water conservation measure in the Candelaria Camposanto Lavanderia. A prototype of this washer was entered in the 2010 SME WESTEC expo student competition in Los Angeles.

The presence of a local professional chapter also provides a unique opportunity for collaboration. Already mentioned was the joint effort in fundraising at Rotary Clubs. More of this joint activity on fundraising is possible. Discussions have also been held on a possible joint project between the student and professional chapter, or having students shadow professionals on their projects. Given the expected 5 year minimum commitment to a community required by EWB-USA, a 
joint project initiative would not be possible until the current projects end. There would also be the need to develop a working relationship that allowed students proper ownership as they work alongside professionals.

\section{Conclusion}

The Western Washington University chapter of Engineers without Borders is currently in the design phase of the clothes washing station in Guatemala. Currently the chapter is deciding if a second assessment trip is necessary in order to complete the final design. As part of standard EWB protocol, EWB-WWU has committed to at least a five year relationship with the community of Candelaria Camposanto in Guatemala in order to help build sustainable projects to improve their quality of life. Through this long term process, students in the chapter build new skill sets by working in small teams, learn about another culture, collaborate with local professionals, and make a meaningful contribution to raising the quality of life for community in Guatemala.

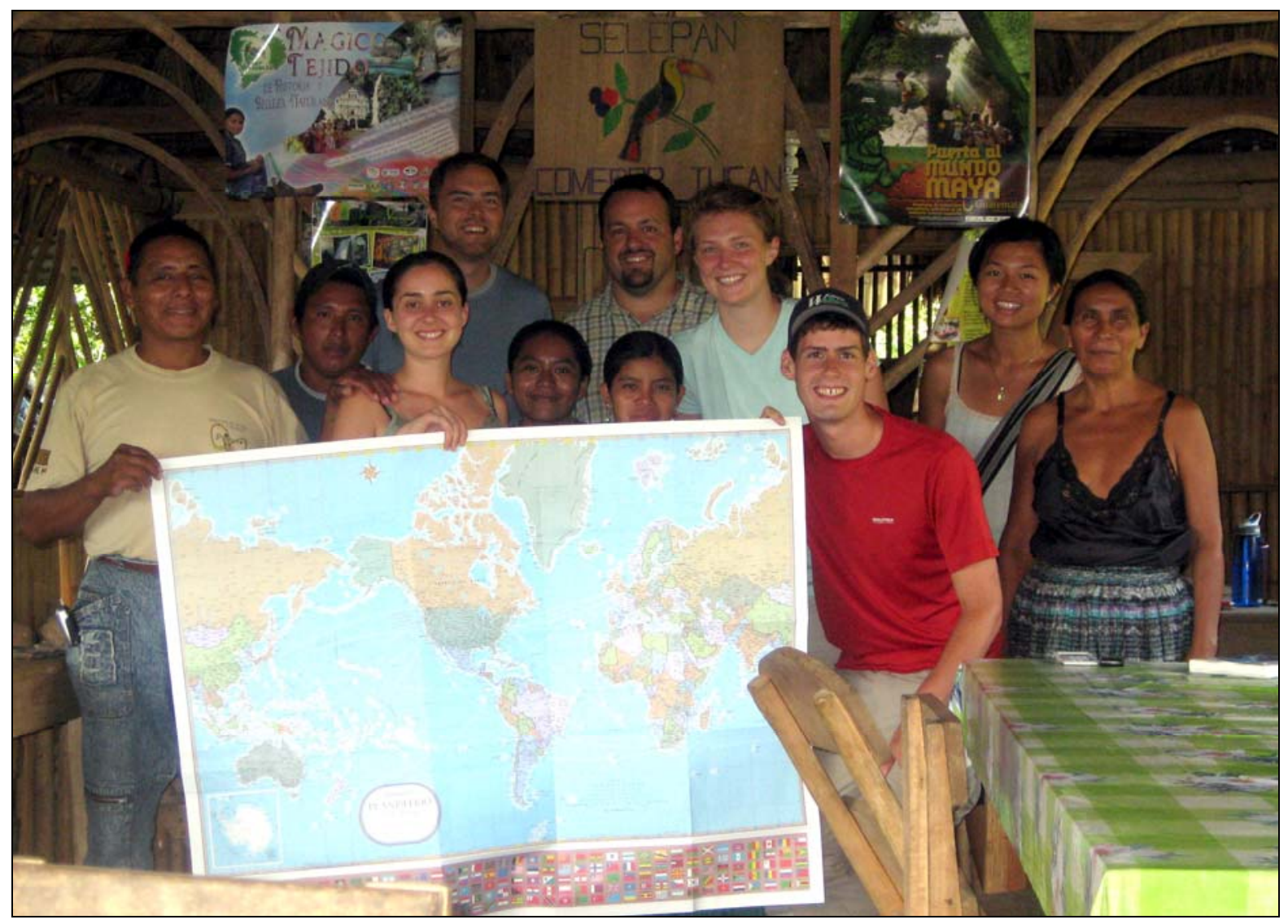

Figure 3: EWB-WWU Members Posing with Members of Candelaria Camposanto

\section{References}

1. http://ewb-usa.org/mission.php accessed January 6, 2011.

2. Smith, B., Ley, D., "Sustainable tourism and clean water project for two Guatemalan communities: A case study”, Desalination 251, 2010, pp 225-232. 